\title{
Egill Skallagrímsson: The first case of Van Buchem disease?
}

\author{
P Stride \\ Physician, Redcliffe Hospital, Redcliffe, Queensland, Australia
}

\begin{abstract}
Egill Skallagrímsson, a tenth-century Viking, was a colourful warrior poet and an early anti-hero. The thickness and strength of his skull and his very ugly facial features with a prominent mandible have suggested to some authorities that Egill suffered from Paget's disease of bone. However, Paget's bone, while thickened, lacks structural integrity, infrequently involves the mandible and is prone to fractures. The more recent discoveries of sclerosing bone diseases, the elucidation of their pathophysiological abnormalities in intracellular signalling in bones and current research on the sclerostin or LRP5 genes suggest Van Buchem disease as a more probable diagnosis, although the hypothesis remains conjecture in the absence of any of his remains.
\end{abstract}

Correspondence to $\mathbf{P}$ Stride, Redcliffe Hospital, Locked Bag I, Redcliffe, Queensland, Australia 4020

tel. +61732567980

e-mail

peter_stride@health.qld.gov.au

Egill Skallagrímsson (ca. 910-990), an Icelandic warrior, runic scholar and poet, was the subject of one of the vibrant Icelandic sagas, Egil's Saga, thought to be written by Snorri Sturlsson in about 1230.' Egill was described as a huge, dark, bald man of extraordinary ferocity and strength who committed his first murder at the age of six when he hit a playmate with an axe. He subsequently travelled as a warrior around northwest Europe, sometimes being banished for violence, and fought for King Athelstan at the battle of Brunanburh in about 937.

Several characteristics emerge from his own writing and that of others, which together build a picture of the man and suggest that he suffered from a chronic disease. $\mathrm{He}$ was said to have ugly facial features like his father and grandfather, and in old age suffered from falls, failing sight and hearing. Egill wrote that he found it hard to control his feet, but attributed this to his poor vision.'

Egill describes himself as particularly ugly in his poetry:

Though I may be ugly,

To accepting my helms'-rock of a head.'

Egil's Saga also describes his distinctive appearance (Figure I):

He had a broad forehead and large brows, a nose that was not long but enormously thick, and lips that, seen through his beard, were both wide and long. $\mathrm{He}$ had a remarkably broad chin, and this largeness continued throughout the jawbone. He was thicknecked and broad-shouldered and, more so than other men, he was hard-looking and fierce when angry. Well built and taller than others, he had thick

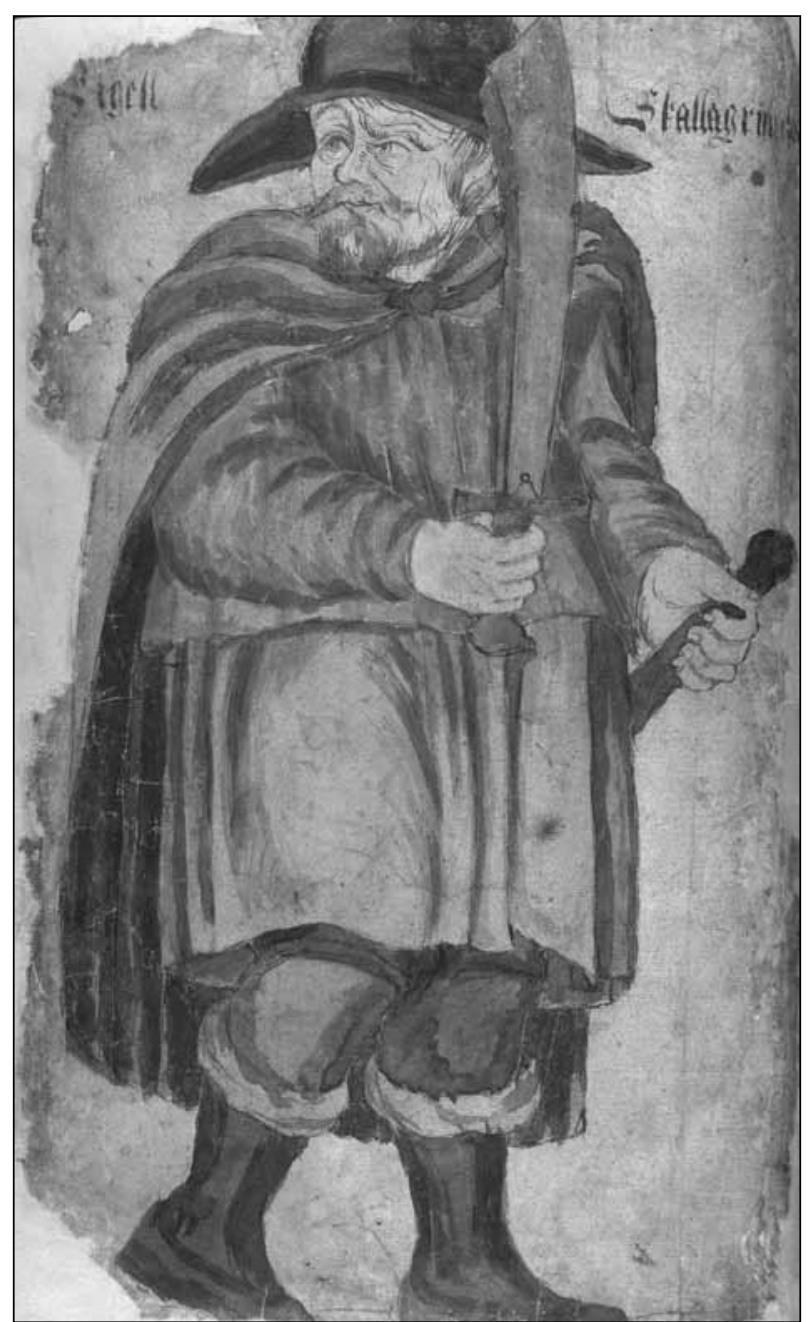

FIGURE I Egill Skallagrímsson as depicted in a seventeenthcentury manuscript of Egil's Saga. (Image courtesy of the Stofnun Árna Magnússonar í íslenskum fræðum @, Reykjavík.) 
wolf-gray hair but was early bald. While he sat as was written above, he jerked one eyebrow down to his chin and lifted the other one up into his hairline; Egill was black-eyed with eyebrows joined. He refused to drink, although drink was brought to him. ${ }^{2}$

Egill was buried in Iceland underneath a church that his niece Thórdís had built at Hrisbru. About I 50 years after his death, when the church at Hrisbru was demolished and a new church built in Mosfell, bones thought to be Egill's were found under the altar. ${ }^{2}$ They were moved to the new graveyard in Mosfell valley. Skapti Thórarinsson, the priest supervising this development noted Egill's skull to be very large, heavy and ridged. The skull was described as 'ridged all over like a scallop shell',' a feature seen in Paget's disease of bone (PDB) (Figure 2). Skapti struck this skull as hard as he could with the blunt side of an axe and failed to break it, or even dent it, although he noted the bone turned white at the point of impact.' From that experiment, the observers considered it would be even less likely that it could be broken in life when covered with skin and hair.

In 2005, Byock and colleagues, carrying out an archaeological dig near Mosfell, reported that a gravesite, possibly that of Egill, had been found under the altar of a church from the settlement period. Unfortunately, no bones were found there, but the excavation continues under the auspices of the Mosfell Archaeological Project. Without this osteological evidence, the hypothesis in this article that Egill suffered from Van Buchem disease (VBD) rather than PDB remains conjecture.

\section{PAGET'S DISEASE OF BONE}

Paget's disease of bone, first described in 1877 by James Paget, ${ }^{3}$ is a chronic disorder. Rare before the age of 40 , it is characterised by focal areas of excessive osteoclastic bone resorption, accompanied by a secondary increase in osteoblastic bone formation. Bone remodelling is disturbed and asynchronous, leading to abnormal bone, which is enlarged, less dense, brittle and prone to breakage. Skull fractures in PDB are not as common as limb fractures as the skull is not a load-bearing bone. Despite bone enlargement and sclerosis, the skull in PDB is believed to be weak. Paget's disease of the pelvis is common, but pelvic fractures are infrequent compared with femoral fractures when these bones are affected by PDB. The disease is most common in the UK and in migrants of Anglo-Saxon origin in Australia, New Zealand and North America, but the disease is uncommon in Scandinavia. ${ }^{4}$

The first suggestion that Egill might have suffered from PDB was made in an Icelandic journal in 1984 by Thordur Hardarson, who went so far as to suggest that PDB be renamed Egill's disease. ${ }^{5}$ The hypothesis was further promoted by Byock' and Buchanan, ${ }^{6}$ who considered but thought unlikely other causes of increased skull density,

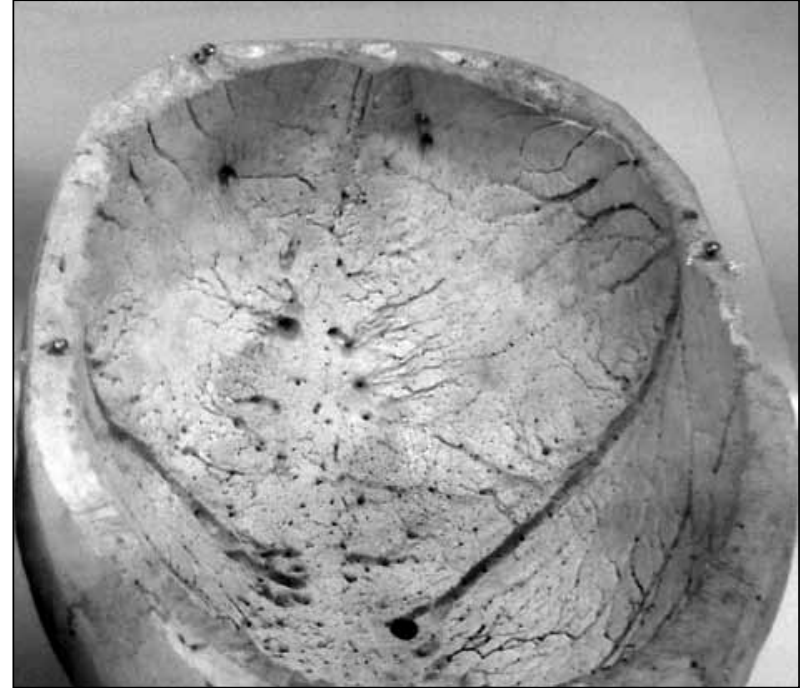

FIGURE 2 Internal view of Paget's skull, showing thickening and scalloping. (Photograph: Andrew Connell. With kind permission of the Royal College of Surgeons of Edinburgh.)

including fluorosis, and hypervitaminosis $A$ and D. Polyostotic fibrous dysplasia, which can cause skull sclerosis and progress to the facial deformity of leontiasis ossica, is another possible explanation, but crucially this is rarely familial. This paper is the first to consider the two types of VBD in the differential diagnosis.

Egill's distinctive facial features, shared with his father and grandfather, suggest a genetic cause for his bony abnormality. Paget's disease can be familial, with 15-20\% of index cases having an affected first-degree relative and generation-generation transmission compatible with autosomal dominance. For the general population, the risk of developing PDB up to the age of 90 is $2 \%$, but this is increased to $9 \%$ if a first-degree relative is affected. ${ }^{4}$ About $30 \%$ of multiplex families and $5-15 \%$ of patients without a family history have sequestosome I (SQSTMI) gene mutations. Abnormal bone signalling has been discovered in PDB, and it is now recognised to be a disease of abnormal osteoclast activity causing weaker bone. Osteoclast precursors transduced with the p62 protein product of SQSTMI are hyper-responsive to the receptor, RANKL.' Paget's disease could therefore be caused by SQSTMI gene mutations, although why the mutation present in all osteoclasts leads to a focal phenotypic disease is obscure. ${ }^{4}$ Other genetic variants have been suggested as candidates for disease susceptibility, ${ }^{8}$ and a viral aetiology with measles or paramyxovirus is also suggested. The aetiology of PDB therefore remains moderately obscure and a direct genetic link is not apparent for all cases.

Although the archaeological methodology may be less accurate than a post-mortem visual inspection, the scalloped appearance of Egill's skull described in the saga is well recognised in PDB. However, skull involvement is not typical. In Chakrovorty's series of 5,000 admissions 
in one year, PDB was identified in 80 patients, of whom skull involvement was present in only 16 and palpable corrugations in six. ${ }^{9}$ Skull involvement is present in less than $50 \%$ of patients with PDB. ${ }^{10}$

The maxilla is involved in 17\% of cases of PDB of the skull, and enlargement of the forehead is the most conspicuous feature." Paget's does not often affect the mandible, only isolated cases having been published. Stafne identified I 38 cases of PDB of the skull and found mandibular disease in only three. ${ }^{12}$ The prominent jaw is therefore not a typical feature of PDB."

Deafness, as suffered by Egill, is the most frequent neurological complication of PDB due to an involvement of the petrous temporal bone. It may be sensorineural from auditory nerve compression or cochlear involvement or conductive in nature from involvement of the ossicles, or a mixture of these two causes. Egill also had failing vision and ataxia, which could be caused by local compressive cranial nerve palsies and brainstem compression from basilar invagination, both features of cranial PDB. Platybasia or, more accurately, an elevation of the posterior fossa with basilar invagination can be found in PDB as the cause of brainstem lesions. Tests of the skull strength in PDB are not available and it would be impossible to obtain patient or relative consent and approval by ethics committees for such studies. Some authors perceive PDB as softening the skull, making it more likely to fracture. ${ }^{10}$

The classic textbook picture of PDB is of a weakened tibia bowed by normal body weight before it fractures. It is hard to perceive that a bone involved by this pathophysiological process would withstand a Viking axe.

\section{VAN BUCHEM DISEASE}

First documented in 1955,VBD is a sclerosing disease of bone. ${ }^{13}$ It is rare, with only 30 cases reported by 1998 , and $50-60$ by $1999 .{ }^{14,15}$ The condition is characterised by progressive osteosclerosis and increased bone density, most marked in the skull and particularly in the mandible, causing a misshapen jaw. It also affects the clavicles, ribs, and diaphyses of long bones. Since the initial publication, it has become clear that VBD has the pedigree features of an autosomal-recessive disorder in which affected individuals are known to be homozygous for mutations close to the sclerostin (SOST) gene. ${ }^{14,15}$ The fact that Egill's father and grandfather had a similar appearance casts doubt on the concept that they all suffered from an autosomal-recessive condition such as VBD type I. However, Iceland was a class-based society with limited population and consanguinity of the three generations of spouses with carriage of the recessive gene is possible. Although Egil's Saga does not report details of those wives or the other siblings of the affected men, an alternative possibility for the three-generation history

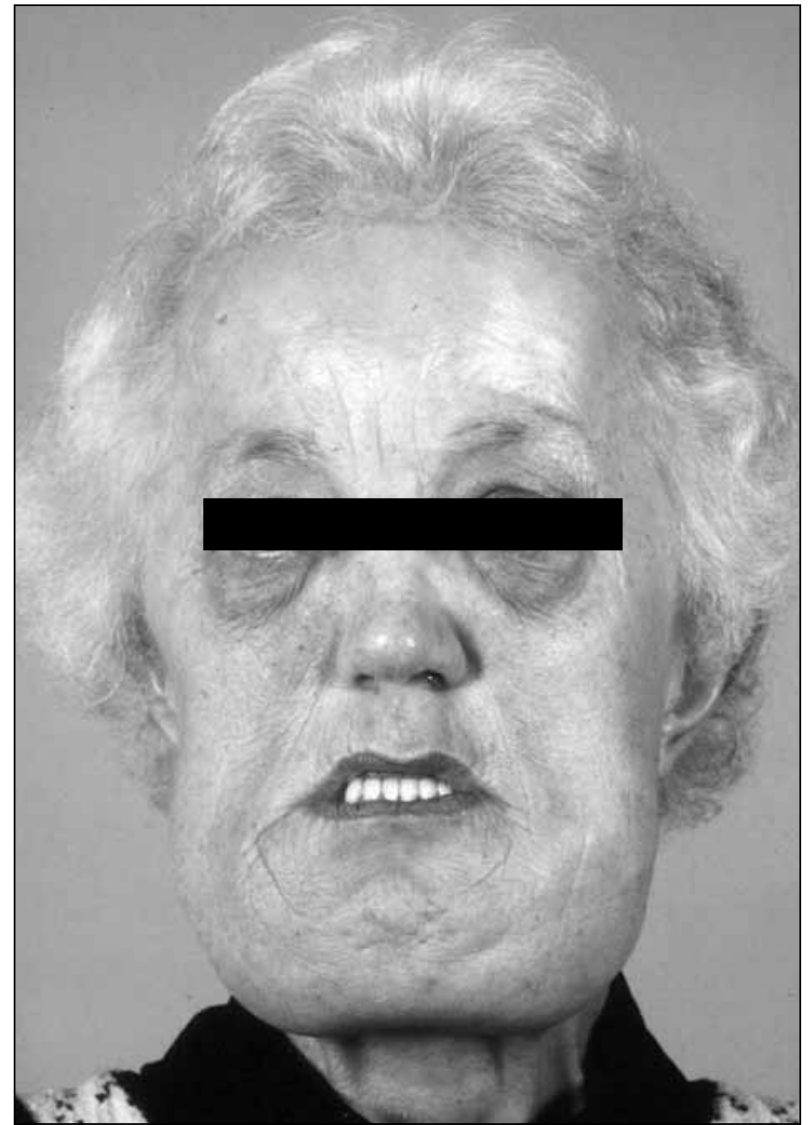

FIGURE 3 Clinical picture of a patient showing the characteristic features of Van Buchem disease: protruding chin, high forehead and facial nerve paralysis. ${ }^{14}$ (With kind permission of Elsevier and thanks to Wim van Hul.)

would be the autosomal-dominant syndrome described by Worth and Wollin in $1966,{ }^{16}$ now usually referred to as VBD type 2.

Autosomal-recessive VBD has been mapped to the short arm of human chromosome $17^{14,15}$ and shown to be due to a homozygous deletion downstream from the SOST gene (i.e. in a non-coding region). Sclerosteosis, a similar but more severe disease, is due to a mutation in the coding region of the sclerostin gene and is associated with reduced life expectancy. In a series of 63 patients with sclerosteosis, mean age at death was 33 , mandibular overgrowth was prominent and no fractures were observed. ${ }^{17}$

Most cases of VBD type I have been detected in the Netherlands or in families who can trace their heritage there, such as the Afrikaner population of South Africa. Van Hul identified II cases of VDB in the small village of Urk (originally an island and now a port in the reclaimed Zuyderzee), who could be traced to a common ancestor nine generations previously. ${ }^{14}$ The current population of about 15,000 can nearly all trace their ancestry back to the I5I inhabitants who survived an outbreak of the plague in $1637 . .^{18}$ Thus the disease mutation has probably existed for centuries. Holland had been subject to 
frequent Viking raids and, as the Vikings were renowned for leaving their DNA behind wherever they went, this might explain the transmission of the disease from Scandinavia to Holland. Perhaps some mitochondrial and Y chromosome DNA studies in the patients from Urk would shed some light on their origins.

Signs and symptoms of VBD are generally observed during early childhood and include facial dysmorphisms, macrocephaly, a prominent forehead, a wide nasal bridge and a broad enlarged prognathic mandible. Other bones, particularly the ribs and clavicles, can show variable degrees of deformity, but gigantism and hand enlargement are features of sclerosteosis rather than VBD. The skull shows irregular ridging. The increasing bone mass subsequently causes compression of cranial nerves, leading to deafness and blindness and, later, cerebellar compression and ataxia.

Dixon et al. described two cases, a brother and sister, with VBD type I. ${ }^{19}$ The female presented at the age of 18 with symptoms and signs of raised intracranial pressure, necessitating surgical removal of a large part of the right parietal bone. She remained well until she developed cerebellar symptoms and signs at the age of 63 . X-rays showed marked thickening of the skull base and the previous craniotomy, as well as thickening of the ribs, clavicles and fingers. She subsequently developed bowel cancer and died with metastatic disease at the age of 68 . Her brother also had surgery for raised intracranial pressure, in his case with bilateral craniotomies at the age of 24 . He became deaf at 30 and at 58 he developed a progressive spastic paraplegia from thickening, particularly of the cervical vertebrae, causing a spinal canal stenosis. Both siblings showed skull enlargement, most markedly in the mandible, but also in the ribs, clavicles and hands, and had normal longevity. They demonstrate the characteristic progress of VBD type I, with cranial palsies and long tracts disease from skull or spinal thickening. The sister developed an unsteady gait, which sounds similar to Egill's gait in later life.

Van Buchem disease type 2 (or Worth disease) was first described in Canadians from the Ontario region ${ }^{16}$ and later in Italians from Sardinia. ${ }^{20}$ Gorlin distinguished this condition from VBD type I in 1977 and considered cranial nerve palsies to be rare. ${ }^{21}$ In 2003, its autosomaldominant inheritance was emphasised as the main clinical distinction from type I VBD. ${ }^{22}$ The disease was also shown to be due to mutations in the LRP5 gene on the long arm of chromosome $11,{ }^{22}$ which codes for LDL receptor-related protein, an important regulator of peak bone mass in vertebrates. In keeping with this function, mutations in LRP5 occur in other disorders of increased bone density.

Egill's prominent jaw as a young man is therefore more in keeping with one of the two types of VBD than with
PDB. Fractures have never been reported in genomically confirmed VBD, clearly unlike PDB. The presumed cranial nerve palsies, headache and long tract problems suffered by Egill are features of both PDB and VBD and do not favour one particular diagnosis. Of the two types of VBD, the transmission through three generations of Egill's family would favour the type 2 autosomal-dominant form, although, with fewer documented cases of Worth disease, ongoing bone deposition throughout adult life is uncertain as late cranial palsies are less frequent.

The failure of Thórarinsson's axe-blow to fracture Egill's skull I 50 years post-mortem suggests bone hardening as seen in VBD and not the PDB form of skull fragility. Bone marker studies of cases of VBD show evidence of increased bone formation with elevated levels of osteocalcin and type I procollagen peptide. ${ }^{23}$

Sclerostin is involved in the Wnt signalling system which promotes bone formation and laboratory studies have shown that sclerostin knockout mice have greatly increased bone density. ${ }^{24}$ Monoclonal antibodies against sclerostin in animal models prevent binding to $\mathrm{Wnt}$ co-receptors, leading to enhanced Wnt signalling and increased bone mass. ${ }^{24}$ Phase I drug testing in healthy humans has demonstrated dose-related increases in bone formation markers and an impressive increase in bone density of $5.3 \%$ at the lumbar spine and $2.8 \%$ at the total hip, compared with placebo, only 85 days after a single dose of antibody. ${ }^{25}$ Teriparatide can achieve an improvement of similar magnitude, but daily injections are required. Phase 2 studies are currently in progress. ${ }^{26}$ This represents a very promising future therapy for osteoporosis.

\section{CONCLUSION}

The deformities and associated neurological problems suffered by Egill could have been due to PDB. However, PBD is a disease of thickened but weakened bone, which is much more likely to break when struck with an axe. Paget's rarely involves the mandible and is not commonly found in young men. Paget's disease of the skull does not often fracture as it is a non-weight bearing bone. The clinical manifestation of skull PDB is basilar impression, a problem caused by weak bone, and the condition is rare in Scandinavia. Once PDB is excluded, there are numerous diseases of bone sclerosis or thickening that are possible, and current knowledge of related gene mutations is rapidly expanding. The 'best match' for Egill needs the following features:

- An autosomal-dominant mode of inheritance, which is more likely to affect people over three generations.

- Presence from an early age.

- Predominant involvement of the mandible with a broad nose.

- Normal life expectancy.

- Neurological problems in later life. 
- An established pedigree traceable over many generations, not an isolated or recent mutation found in a family over one or two generations.

- Geographical and genetic connection to Scandinavia.

Van Buchem disease fulfils most of these requirements. Since not much is known so far of life expectancy, neurological features in later life, multigenerational pedigree or links to Scandinavia for type 2 VBD, at this stage type I VBD, although not autosomal-dominant, seems the more probable diagnosis for Egill's condition.

\section{REFERENCES}

I Byock J. Skull and Bones in Egils saga: a Viking, a grave, and Paget's disease. Viator 1993; 24:23-50.

2 The story of Egil Skallagrimsson. Trans. WC Green. London: Elliot Stock; 1893. Available from: http://www.sacred-texts.com/neu/ egil/index.htm

3 Paget J. On a form of chronic inflammation of bones (osteitis deformans). Trans Med-Chir Soc 1877; 60:37-63.

4 Walsh JP. Paget's disease of bone. Med J Aust 2004; I81:262-5.

5 Hardarson T, Snorradottir E. Egil's or Paget's disease? BMJ 1996; 313:1613-4.

6 Buchanan WW. Did the tenth-century Viking Egil Skallagrimsson (c.AD 910-990) have Paget's disease? J R Coll Physicians Edinb 2004 34:243-6.

7 Kurihara N, Hiruma Y, Zhou H et al. Mutation of the sequestosome I (p62) gene increases osteoclastogenesis but does not induce Paget disease. J Clin Invest 2007; II7:133-42. doi:10.1172/ JCl28267

8 Albagha OM, Visconti MR, Alonso $N$ et al. Genome-wide association study identifies variants at CSFI, OPTN and TNFRSFIIA as genetic risk factors for Paget's disease of bone. Nature Genet 2010; 42:520-4. doi:10.1038/ng.562

9 Chakravorty N, Das S, Kataria M. Corrugation of the skull in Paget's disease of bone. Postgrad Med J 1977; 53:40-6. doi:10.1 I36/ pgmj.53.615.40

10 Raubenheimer PJ, Taylor AG, Soule SG. Paget's disease complicated by hydrocephalus and syringomyelia. Br J Neurosurg 2002; 16:5I3-6. doi:I0.1080/026886902320909|78

II Lucas R. The jaws and teeth in Paget's disease of bone.J Clin Path 1955; 8: 195.

12 Stafne EC,Austin LJ.A study of dental roentgenograms in cases of Paget's disease, osteitis fibrosis cystica and osteoma. J Am Dent Assoc 1938; 25:1210.

I3 Van Buchem F, Hadders H, Ubbens R. An uncommon familial systemic disease of the skeleton: hyperostosis corticalis generalisata familiaris. Acta Radiol 1955; 44:109-20. doi:10.3109/00016925509170789

I4 Van Hul W, Balemans W, Van Hul E et al. Van Buchem disease (hyperostosis corticalis generalisata) maps to chromosome |7q12-q21. Am J Hum Genet 1998; 62: 391-9. doi:10.1086/30172।
The increased understanding of the molecular interactions and signalling pathways of sequestosome, sclerostin and LRP5 has provided future tools to confirm or exclude Egill's diagnosis and that of his father and grandfather. Only tiny amounts of preserved bony tissue are required to separate enough DNA to test for relevant mutations. If Egill's bony remains are eventually identified, the 'outstandingly ugly' characteristics of the Icelandic men of Myrar, who claim descendence from Egill, may be better understood in retrospect.
I5 Balemans W,Van Den Ende J, Freire Paes-Alves A et al. Localization of the gene for sclerosteosis to the van Buchem disease-gene region on chromosome 17q12-q21. Am J Hum Genet 1999; 64:166I-97. doi:10.1086/3024I6

16 Worth HM, Wollin DG. Hyperostosis corticalis generalisata congenital.J Can Assoc Radiol 1966; 17:67-74.

17 Hamersma H, Gardner J, Beighton P. The natural history of sclerosteosis. Clin Genet 2003; 63:192-7. doi:10.1034/j.I399-0004. 2003.00036.x

18 Jacobs P. Van Buchem disease. Postgrad Med J 1977; 53:497-505. doi:I0.I I36/pgmj.53.622.497

19 Dixon JM, Cull RE, Gamble P. Two cases of Van Buchem's disease. J Neurol Neurosurg Psychiatr 1982; 45:913-8. doi:10.1136/ jnnp.45.10.913

20 Scopelliti D, Orsini R, Ventucci E et al. [Van Buchem disease. Maxillofacial changes, diagnostic classification and general principles of treatment]. Minerva Stomatol 1999; 48:227-34. In Italian.

21 Gorlin RJ, Glass L. Autosomal dominant osteosclerosis. Radiology I977; 125:547-8.

22 Van Wesenbeeck L, Cleiren E, Gram J et al. Six novel missense mutations in the LDL receptor-related protein 5 (LRP5) gene in different conditions with an increased bone density. Am J Hum Genet 2003; 72:763-7I. doi:I0.1086/368277

23 Wergedal JE,Veskovic K, Hellan M et al. Patients with Van Buchem disease, an osteosclerotic genetic disease, have elevated bone formation markers, higher bone density and greater derived polar moment of inertia than normal. J Clin Endocrinol Metab 2003; 88:5778-83. doi:10.1210/jc.2003-03020।

24 Li X, Ominsky MS, Warmington KS et al. Sclerostin antibody treatment increases bone formation, bone mass and bone strength in a rat model of postmenopausal osteoporosis. J Bone Miner Res 2009; 24:578-88. doi: I 0. I359/jbmr.08। 206

25 Padhi D, Jang G, Stouch B et al. Single-dose, placebo-controlled, randomised study of AMG 785, a sclerostin monoclonal antibody. J Bone Miner Res 201 I; 26:19-26. doi:10.1002/jbmr.173

26 Paszty C, Turner $\mathrm{CH}$, Robinson MK. Sclerostin: a gem from the genome leads to bone-building antibodies.J Bone Miner Res 2010; 25: 1897-904. doi:10.1002/jbmr.161 